\title{
Alinhamento entre estratégia de negócios e melhoria de processos de software: um roteiro de implementação
}

\author{
Regina Asato ${ }^{\mathrm{a}, *}$, Mauro Mesquita Spinola ${ }^{\mathrm{b}}$, Ivanir Costa ${ }^{\mathrm{c}}$, \\ Walter Henrique De Farias Silva ${ }^{d}$ \\ a,*regina.asato@uol.com.br, UNIP, Brasil \\ bmauro.spinola@.usp.br, UNIP, Brasil \\ cicosta11@terra.com.br, UNIP, Brasil \\ dwalter-henrique@uol.com.br, UNIP, Brasil
}

\begin{abstract}
Resumo
As ações de melhoria dos produtos e processos de software, para um melhor atendimento dos objetivos de negócio de uma organização, devem estar associadas às estratégias competitivas do mercado. Este trabalho descreve um roteiro que traduz os objetivos estratégicos de organizações de software em indicadores de processo gerenciáveis. O Balanced Scorecard (BSC) é utilizado como base desse roteiro, sendo complementado pelas práticas do modelo Practical Software Measurement (PSM). 0 estudo está baseado em uma pesquisa bibliográfica dos conceitos e a aplicação de uma pesquisa-ação. A estratégia de pesquisa-ação permite o refinamento do roteiro, o aprendizado dos participantes e a melhoria da aplicação do próprio método. A execução das etapas metodológicas resultou na definição do mapa estratégico e seus desdobramentos em uma organização desenvolvedora de software. 0 resultado final é um roteiro que permite a implementação do alinhamento estratégico de negócios e a melhoria de processos em organizações desenvolvedoras de software.
\end{abstract}

Palavras-chave

Estratégia de negócios. Melhoria de processos de software. BSC. PSM.

\section{Introdução}

Segundo o Ministério da Ciência e Tecnologia (MCT), países como China e Índia estão estreitando as relações na área de software para garantir o posto de países mais favoráveis para a terceirização no setor de tecnologia. Além disso, relatórios do MCT informam que a exportação do produto no Brasil ainda é muito pequena (BRASIL, 2005). Por outro lado, o volume de investimento mundial em software tende a aumentar muito nos próximos anos. Nesse cenário, as organizações brasileiras do segmento buscam implementar modelos de qualidade reconhecidos no mercado internacional visando ao aumento de competitividade e a exportação de software.

A visão da tecnologia da informação (Tl) como arma estratégica competitiva tem sido discutida e enfatizada, pois não só sustenta as operações do negócio existentes, como também permite que se viabilizem novas estratégias empresariais (LAURINDO, 2003). Segundo Laurindo (2000), as empresas especializadas em software, por questão de competitividade, buscam utilização de técnicas e ferramentas mais modernas, apresentando maior produtividade no desenvolvimento de sistemas, o que provoca um impacto direto na eficiência dessa atividade. 0 autor afirma que os investimentos em tecnologia são dirigidos aos negócios, ou seja, o novo software é desenvolvido para atender aos negócios. A necessidade de software torna-se cada vez mais evidente, gerando oportunidade de negócios para os produtores desse segmento.

Em busca da competitividade, as empresas desenvolvedoras de software necessitam investir na melhoria dos seus processos. No entanto, algumas 
empresas retardam ou adiam o investimento em processos de melhoria de software devido à falta de entendimento sobre como essa implementação pode ser bem-sucedida (GUERRERO; ETEROVIC, 2004).

Os investimentos por iniciativa de uma gerência ou coordenação, realizados de forma isolada, tendem a ser interpretados como custo. lsso ocorre devido à falta de compreensão das áreas de negócio sobre a importância da melhoria do processo de software e pela falta de demonstração de resultados diretos nos negócios da organização. Além disso, os benefícios dos investimentos em implementação de melhoria de processos nem sempre são percebidos imediatamente. Por esse motivo, muitas empresas desistem ou suspendem os investimentos antes de atingir seus objetivos.

Surgem então as seguintes questões:

- Como pode ser feito o alinhamento entre a estratégia e os investimentos em melhorias de processos de software?

- Como planejar e implementar as estratégias adotadas?

A pesquisa bibliográfica, com o intuito de buscar as respostas a esses questionamentos, direcionou os estudos para o Balanced Scorecard (BSC).

0 BSC é o modelo proposto por Kaplan e Norton (2004) e trata-se de uma ferramenta que traduz a missão e a estratégia das empresas em um conjunto abrangente de medidas de desempenho. Seu propósito é alinhar as estratégias de unidades de negócio à estratégia corporativa, transformando a missão, a visão e a estratégia da organização em objetivos e metas diferenciados de acordo com quatro perspectivas: financeiras, do cliente, dos processos internos e de aprendizado e crescimento.

O BSC funciona como um painel de controle para visualizar a organização em várias perspectivas de uma só vez. Na base do mapa estratégico temos a perspectiva de aprendizado e crescimento, que identifica os ativos intangíveis mais importantes. Além disso, contribui para que as empresas acompanhem as estratégias adotadas e verifiquem os retornos positivos de modo a justificar os investimentos.

Os autores afirmam que o modelo permite avaliar até que ponto as unidades de negócio de uma empresa geram valor para os clientes atuais e futuros. Além disso, permite identificar como cada unidade deve aperfeiçoar suas capacidades internas e os investimentos necessários em pessoal, sistemas e processos visando melhorar o desempenho futuro.

0 estudo bibliográfico do modelo BSC mostrou a necessidade de pesquisa complementar de modelos de indicadores de desempenho e modelos de planejamento e implementação de processos. Por esse motivo, foram estudados os modelos PSM (Practical Software Measurement) e PMBOK (Project Management Body of Knowledge). As melhores práticas do BSC agregando aspectos críticos relacionadas a gerenciamento de projetos, mudanças, risco e Quality Assurance têm sido tema de outros trabalhos de pesquisa. Segundo Papalexandris et al. (2005), a principal contribuição é detalhar "como" implementar alinhamento estratégico nas organizações utilizando o BSC.

0 objetivo desta pesquisa é desenvolver um roteiro para a implementação do alinhamento entre a estratégia de negócios e a melhoria de processos de software em empresas desenvolvedoras de software. Esse roteiro tem como base um quadro teórico resultante da pesquisa bibliográfica e subsídios fornecidos por uma pesquisa-ação.

0 texto está divido em cinco seções incluindo esta. A seção 2 apresenta os conceitos e a fundamentação teórica que trazem subsídios para o processo de implementação do mapa estratégico, seus desdobramentos e indicadores. A seção 3 mostra a metodologia de pesquisa aplicada. A seção 4 apresenta a execução da pesquisa-ação e os resultados obtidos em cada etapa. Finalmente, a seção 5 traz a conclusão deste trabalho.

\section{Referencial teórico}

Os conceitos apresentados nesta seção permitem compreender e embasar o processo de alinhamento estratégico e a implementação de melhorias de processos. Os conceitos sobre empresas desenvolvedoras de software elucidam a área de atuação, foco desta pesquisa. Os estudos indicaram o BSC (Balanced Scorecard) como modelo de referência do roteiro-base proposto. Para melhor compreensão dos elementos do BSC, foram detalhados também conceitos sobre estratégia e indicadores. O PSM (Practical Software Measurement) foi utilizado na definição do processo de medição e da implementação dos indicadores estratégicos. O PMBOK (Project Management Body of Knowledge) foi utilizado como referência para o planejamento do plano de implementação do processo de melhoria do processo.

\subsection{Empresas desenvolvedoras de software}

Sommerville (2007) classifica as empresas que atuam neste setor de software como "prestadoras de serviços" ou "desenvolvedoras de produtos". 
Por sua vez, o britânico Department of Trade and Industry (2004) define que esse mercado pode ser dividido entre empresas que prestam serviços de software (para um cliente apenas) e desenvolvedoras de produtos de software (para mais de um cliente). Os produtos de software incluem aplicativos, desenvolvimento de aplicativos e infraestrutura de sistemas. Os serviços de software incluem consultoria em processos e soluções de negócios e em tecnologia da informação, integração de sistemas, terceirização de processos de negócio.

Veloso, Botelho e Gianelli (2003) utilizam o conceito de categorias de produtos, as quais podem ser: software pacote, software customizado e software embutido. As categorias serviços de software incluem terceirização de operações, desenvolvimento de software, integração de sistemas e consultoria especializada.

Os produtos e serviços de software registram altos investimentos em desenvolvimentos que não alcançaram seus objetivos (BRASIL, 2005). A participação no mercado de software de forma competitiva exige mecanismos de gestão empresarial envolvendo questões relacionadas ao planejamento estratégico, programas e sistemas de qualidade, processos de desenvolvimento, pesquisas de expectativas e satisfação do cliente, capacitação de recursos humanos, entre outros. Essas exigências visam garantir o atendimento dos objetivos de negócio da organização, gerando lucro e perenidade. Além disso, muitas organizações têm dificuldades em relacionar as metas de melhoria de processos com as expectativas dos clientes. Portanto, determinar uma base sólida para sustentar os esforços em melhoria de processos (MURUGAPPAN; KEENl, 2003).

Vahaniitty e Rautiainem (2005) afirmam que, para as empresas de software, o sucesso de seus produtos e serviços depende de outros fatores que não apenas o desenvolvimento de software. As preocupações com atualização tecnológica continuam, mas agregam também gerenciamento do portfólio e estratégias de mercado.

Por esse motivo, o alinhamento estratégico torna-se fundamental para que os investimentos em melhoria de processos de software sejam percebidos através de resultados efetivos nos objetivos de negócio da organização.

Esta pesquisa propõe o desenvolvimento de um roteiro para a implementação do alinhamento entre a estratégia de negócios e a melhoria de processos de software em empresas desenvolvedoras de software. O BSC, cujo conceito é apresentado a seguir, foi aplicado como o modelo de referência do roteiro proposto.

\subsection{BSC - Balanced Scorecard}

O BSC é um efetivo e compreensivo método para ajudar as organizações a alinhar objetivos estratégicos e indicadores de desempenho (MAIR, 2002). Tal afirmação sugere que, para o melhor entendimento do BSC, os conceitos de estratégia e indicadores de desempenho devem ser abordados.

Porter (1986) afirma que ter uma estratégia é a única forma de garantir uma posição singular e diferenciada que permite enfrentar os rivais. Enfatiza ainda que, devido à pressão pela hipercompetição, as empresas estão se limitando a copiar seus concorrentes ao invés de elaborar uma estratégia.

Na visão de Montgomery e Porter (1998), a essência da formulação estratégica é lidar com a competição. Destacam como elementos da competição na luta por participação de mercado: os clientes, os fornecedores, os novos entrantes em potencial e os produtos substitutos.

Para Kaplan e Norton (2004), a implementação da estratégia começa pela capacitação e envolvimento das pessoas que devem executá-la. Os autores afirmam que os sistemas de mensuração das organizações determinam o comportamento dos gerentes e empregados. Os indicadores contábeis e financeiros tradicionais (retorno de investimento e lucro por ação) podem ser interpretados de forma enganosa, quando se trata de atividades exigidas pelo ambiente competitivo da atualidade, que requer melhoria contínua e inovação. Os indicadores tradicionais atenderam bem na era industrial, mas estão defasados para o momento atual.

Muscat e Fleury (1993) afirmam que um estudo sobre indicadores da qualidade e produtividade na indústria brasileira mostrou que a escolha dos indicadores para medição e monitoramento está diretamente vinculada à estratégia competitiva definida pela empresa e aos fatores críticos e sucesso (FCSs). Os FCSs são os fatores identificados pela organização nos quais deseja ser bem-sucedida e, necessariamente, ter bons resultados. Uma vez identificados os FCSs do negócio deve-se relacioná-los aos requisitos de negócio para $\mathrm{Tl}$ (FERNANDES; ABREU, 2006).

Para Kaplan e Norton (2004), os FCSs remetem aos indicadores de gestão da empresa. Quando se identificam os FCSs, estão sendo identificadas as variáveis que devem ser mensuradas e, se possível, aperfeiçoadas, para alcançar os objetivos da empresa através de sua estratégia competitiva.

Segundo Pressman (1992), as medições são necessárias para determinar se o processo está melhorando ou não. Os indicadores possibilitam o 
estabelecimento de metas quantificadas, bem como a análise crítica do desempenho para tomada de decisão e replanejamento (TAKASHINA; FLORES, 1999).

$\mathrm{Na}$ visão de Kaplan e Norton (2004), os indicadores possibilitam acompanhar o andamento de um processo e identificar problemas e riscos em potencial antes de se tornarem críticos. Permitem, ainda, controlar qualidade e produtividade, obtendo informações importantes para a eficiência de um processo e auxílio na tomada de decisões. Portanto, a definição dos indicadores é de suma importância, pois uma escolha inadequada poderá levar a conclusões errôneas. Os autores afirmam que uma das mais sérias deficiências da maioria das empresas é relacionar a estratégia a longo prazo às ações a curto prazo. Afirmam ainda que ter um bom planejamento estratégico não é suficiente para garantir que as ações de implementação ocorrerão como desejadas.

Para os autores, o sistema de medição deve tornar explícitas as relações entre os objetivos e as medidas nas várias perspectivas para que elas possam ser gerenciadas e validadas. A cadeia de causa e efeito deve permear todas as quatro perspectivas de um balanced scorecard. A relação de causa e efeito garante um encadeamento entre os objetivos das perspectivas de modo a refletir as relações de causa e efeito assumidas na formulação das estratégias.

Kaplan e Norton (2004) propuseram também o mapa estratégico definido como uma arquitetura genérica para a descrição da estratégia de maneira coesa, integrada e sistemática. Em outras palavras, o mapa estratégico fornece uma representação visual dos objetivos estratégicos de uma organização, bem como as relações de causa e efeito entre elas.

0 modelo BSC recomenda gerar e monitorar indicadores de desempenho, mas não detalha como executar essa tarefa. O PSM, cujo conceito é apresentado a seguir, detalha as atividades a serem executadas para a elaboração do plano de medição. A contribuição desse modelo é fundamental para o roteiro proposto nesta pesquisa. 0 roteiro proposto aplica os processos do PSM na definição dos indicadores que devem ser monitorados pela organização. Por sua vez, esses indicadores estão alinhados com as estratégias de negócio da organização. As estratégias de negócios foram traduzidas em objetivos estratégicos utilizando os conceitos do BSC.

\subsection{PSM - Practical Software Measurement}

Existem vários processos de medição de software propostos na literatura e aplicados na prática. No entanto, sua aplicação alinhada à estratégia da organização ainda levanta muitas dúvidas, sobretudo referentes ao alinhamento com as definições estratégicas propostas em modelos como o BSC. Este trabalho propõe a aplicação dos conceitos do PSM na definição dos indicadores visando oferecer um método para a implementação de um plano de medição consistente.

Segundo Shibuya (2007), a implementação do BSC sugere a identificação de indicadores de desempenho para que estes sejam constantemente avaliados e monitorados por todos os envolvidos. Esse método contribui para uma análise constante e periódica das metas propostas, permitindo um controle amplo e objetivo. Dessa forma, os envolvidos podem analisar os resultados que estão efetivamente sendo alcançados pela organização.

Card (2003) propõe a integração do PSM com o BSC comparando a lista de categorias de informação com as quatro perspectivas apresentadas por Kaplan e Norton (2004).

O PSM é o modelo que foi elaborado e vem sendo atualizado por renomados profissionais da área de Software Process Improvement como John McGarry, David Card e Beth Layman. O PSM foi utilizado como base para a elaboração da Process Area Measurement and Analysis do CMMI (PRACTICAL.... 2006). 0 PSM foi formalizado através do padrão ISO/IEC 15939 - Software Engineering - Software Measurement Process Framework.

O PSM é um modelo para a estruturação da atividade de mensuração em um projeto de software (CARD, 2003). Na prática, o PSM define como especificar formalmente as medidas a serem utilizadas e como conduzir o processo de medição. Esses objetivos são atingidos através de dois modelos: o modelo de informação e o modelo de processo.

0 modelo de informação do PSM é uma estrutura para a definição das medidas a serem utilizadas em um projeto. 0 modelo define os seguintes conceitos:

- Atributo - propriedade relevante do ponto de vista das necessidades de informação;

- Método - operação que mapeia o atributo para uma escala;

- Medida Básica - valor resultante da aplicação do método a um atributo;

- Função - algoritmo que combina duas ou mais medidas básicas;

- Medida derivada - valor resultante da aplicação da função;

- Modelo - algoritmo combinando medidas e critérios de decisão;

- Indicador - estimativa ou avaliação que provê uma base para a tomada de decisão. 
0 modelo de processo do PSM direciona a condução das atividades de medição em um projeto de desenvolvimento de software. 0 processo envolve os seguintes subprocessos:

- Planejar mensuração - compreende as atividades de identificar e priorizar as necessidades de informação; selecionar e especificar as medidas; integrar mensuração aos processos dos projetos. 0 PSM define as informações nas seguintes categorias: prazo e progresso, recursos e custo, tamanho e estabilidade do produto, qualidade do produto, performance do processo, eficácia da tecnologia e satisfação do cliente. O PSM inclui tabelas de correspondência entre as categorias de informação, conceitos mensuráveis e medidas candidatas;

- Executar mensuração - abrange as atividades de coletar e processar dados, analisar dados, produzir recomendações;

- Avalizar mensuração - compreende as atividades de avaliar medidas, avaliar o processo de mensuração, atualizar a base de experiência, identificar e implementar melhorias;

- Estabelecer e sustentar o comprometimento.

\subsection{PMBOK - Project Management Body of Knowledge}

No BSC é prevista a etapa de identificar os planos de ação para cada objetivo estratégico. Segundo Kaplan e Norton (2004), é comum a identificação de um número incontável de ações a serem executadas. A proposta é aplicar os conceitos do PMBOK para executar o planejamento detalhado de cada plano. Dessa forma, será possível obter informações consistentes para apoio à tomada de decisão na priorização dos planos de ação.

Segundo o PMBOK (PROJECT..., 2008), um projeto é um empreendimento temporário com o objetivo de criar um produto ou serviço único.

Na visão de Possi (2004), o gerenciamento de projetos é a aplicação de conhecimentos, habilidades, ferramentas e técnicas nas atividades do projeto para que se possa alcançar o que os interessados (stakeholders) no projeto desejam e as expectativas do projeto como um todo.

O PMBOK é um guia chamado de "corpo de conhecimento em gerência de projetos", que descreve a somatória de conhecimentos e melhora as práticas dentro da gerência de projetos (PROJECT..., 2008). O PMBOK padroniza os termos utilizados na gerência de projetos. É um material genérico que serve para gerenciar projetos de todas as áreas de conhecimento, ou seja, tanto para a construção de um edifício como para a produção de software.
O PMBOK foi criado pelo PMI (Project Management Institute), uma associação de profissionais de gerenciamento de projetos que existe desde 1969. Essa associação criou, em 1986, a primeira versão do PMBOK. Segundo o PMBOK, a meta do gerenciamento de projetos é conseguir exceder as necessidades e expectativas dos stakeholders. Porém, satisfazer ou exceder essas necessidades envolve um balanceamento entre as várias demandas concorrentes em relação ao escopo, tempo, custo e qualidade (objetivos do projeto); stakeholders com necessidades e expectativas diferenciadas; requisitos identificados (necessidades) e requisitos não identificados (expectativas).

0 PMBOK organiza os processos de gerenciamento de projetos em cinco grupos, cada um contendo um ou mais processos:

- Processos de iniciação - autorização do projeto ou fase;

- Processos de planejamento - definição e refinamento dos objetivos e seleção da melhor alternativa de ação para alcançar os objetivos do projeto;

- Processos de execução - coordenar pessoas e outros recursos para realizar o plano;

- Processos de controle - assegurar que os objetivos do projeto estejam sendo atingidos, tomando ações corretivas quando necessárias;

- Processos de encerramento - formalizar a aceitação do projeto ou fase e encerrá-lo de uma forma organizada.

Os processos do PMBOK estão organizados em nove áreas de conhecimento, e dentro dessas áreas os cinco grupos de processos acima descritos podem ocorrer. Cada uma das nove áreas de conhecimento possui seus processos, que são ligados por suas entradas e saídas. Cada processo pode ser descrito por suas entradas, que são definidas como documentos ou itens documentáveis que influenciarão o processo. As ferramentas e técnicas são representadas pelos mecanismos aplicados às entradas para gerar as saídas; e as saídas, pelos documentos ou itens documentáveis resultantes do processo. As nove áreas são: integração, comunicação, qualidade, escopo, custo, tempo, risco, recursos humanos e aquisição.

\section{Abordagem metodológica}

A metodologia deste trabalho inicia-se com um levantamento bibliográfico para a compreensão dos conceitos. Com base neste levantamento foi elaborado o roteiro-base proposto, visando a implementação do alinhamento estratégico de negócios com a melhoria de processo de software. 
0 estudo inicial das estratégias metodológicas levou à escolha da pesquisa-ação, pois Thiollent (2005) afirma que esta permite dar ao pesquisador e ao grupo de participantes os meios de se tornarem capazes de responder com maior eficiência aos problemas da situação em que vivem, sob a forma de diretrizes de ação transformadora.

Segundo Thiollent (2005), as fases de uma pesquisa-ação são flexíveis e proporcionam a execução de uma sequência cíclica de fases em função das circunstâncias e da dinâmica do grupo de pesquisa em relação à situação investigada. A aplicação da abordagem de uma pesquisa-ação permitiu o refinamento gradativo do roteiro, o aprendizado dos participantes e a melhoria da aplicação do próprio método. Nessa metodologia, os pesquisadores e os participantes representativos da situação ou do problema estão envolvidos de modo cooperativo ou participativo. As fases definidas por Thiollent (2005) para projetos de pesquisa-ação foram adaptadas visando atender as necessidades deste trabalho. 0 Quadro 1 apresenta a estrutura da pesquisa-ação deste estudo. A estrutura foi adaptada utilizando como base os processos do PMBOK. 0 quadro apresenta, também, as atividades que devem ser executadas em cada processo e a cobertura em relação às fases propostas por Thiollent.
Este artigo relata as principais atividades da pesquisa-ação. Ao selecionar a unidade de análise apropriada, os critérios recomendados para a implementação do BSC foram considerados. A escolha considerou uma unidade de negócios com atividades de vendas, operações, marketing e serviços, que tem clientes próprios e medidas de desempenho financeiro.

A empresa foco desta pesquisa atua no mercado de software nacional desde 1993 e tem representação no mercado internacional desde 1998. É composto por seis unidades de negócios que possuem produtos e serviços próprios com clientes e objetivos estratégicos independentes. A unidade de análise escolhida foi a Strategic Products. Esta unidade oferece soluções de software como produtos para o mercado financeiro. Definiu em seu planejamento estratégico oferecer soluções que atendam às resoluções estabelecidas pelo Banco Central como o risco operacional. A motivação da unidade negócio em participar desta pesquisa encontra-se na afinidade do assunto com um dos produtos oferecidos pela unidade. Os critérios estabelecidos pela empresa para a escolha a unidade de análise foram: importância representativa para a organização, expectativa de crescimento e meta de aumentar a satisfação do cliente.

Quadro 1. Estrutura de processos e atividades da pesquisa-ação.

\begin{tabular}{|c|c|c|}
\hline Processos PMBOK & Atividades da pesquisa-ação adaptada & $\begin{array}{c}\text { Fases da pesquisa-ação } \\
\text { por Thiollent }\end{array}$ \\
\hline \multirow{5}{*}{ 1. Iniciação } & 1.1. Objetivo da pesquisa & 0 problema \\
\hline & 1.2. Questões da pesquisa & 0 problema \\
\hline & 1.3. Proposição do estudo & A hipótese \\
\hline & 1.4. Seleção da unidade de análise & 0 campo de observação \\
\hline & 1.5. Caracterização da empresa & 0 campo de observação \\
\hline \multirow{6}{*}{ 2. Planejamento } & 2.1. Definição da equipe de pesquisa & 0 seminário \\
\hline & 2.2. Obtenção do comprometimento da equipe sobre o processo a ser investigado & 0 seminário \\
\hline & 2.3. Elaboração do macro-planejamento da pesquisa & 0 seminário \\
\hline & 2.4. Planejamento dos ciclos da pesquisa-ação & 0 seminário \\
\hline & 2.5. Definição do cronograma das atividades e metas a serem alcançadas & 0 seminário \\
\hline & 2.6. Detalhamento do planejamento do ciclo da pesquisa & 0 seminário \\
\hline \multirow{4}{*}{ 3. Execução } & 3.1. Execução do planejamento do ciclo da pesquisa & Coleta de dados \\
\hline & 3.2. Coleta dos documentos de evidências & Coleta de dados \\
\hline & 3.3. Elaboração do relatório de pesquisa & Coleta de dados \\
\hline & 3.4. Interpretação das evidências & Coleta de dados \\
\hline \multirow{4}{*}{ 4. Controle } & 4.1. Registro das lições aprendidas & Aprendizagem \\
\hline & 4.2. Aplicação do questionário aos envolvidos & Saber formal e informal \\
\hline & 4.3. Divulgação dos resultados parciais & Divulgação dos resultados \\
\hline & 4.4. Refinamento do roteiro-base & Plano de ação \\
\hline \multirow{2}{*}{ 5. Encerramento } & 5.1. Elaboração do roteiro final & Plano de ação \\
\hline & 5.2. Encerramento da pesquisa-ação & Divulgação dos resultados \\
\hline
\end{tabular}

Fonte: os autores. 
A equipe definida para a condução e execução desta pesquisa foi composta por: um pesquisador; um diretor executivo e três coordenadores. Os participantes da pesquisa tinham como perfil: graduação em Ciências da Computação, especialização em Gestão de Projetos e Negócios e mestrado em Engenharia de Produção (em andamento); profissionais na faixa etária entre 30 e 50 anos com tempo de serviço variando de 2 a 10 anos na empresa; área de atuação foi, na sua maior parte, em desenvolvimento de sistemas, além de cinco anos em consultoria de processos de software.

A participação de um dos autores como pesquisador foi possível devido ao longo tempo de relacionamento com a empresa. A atuação se deu desde o planejamento preliminar da pesquisa até a finalização deste trabalho.

A aplicação da abordagem de uma pesquisaação permitiu o refinamento gradativo do roteirobase, o aprendizado dos participantes e a melhoria da aplicação do próprio método. Ao término da execução das sequências cíclicas foi obtido o roteiro final objeto deste trabalho. No macroplanejamento, a realização de dois ciclos da pesquisa-ação foi definida:

- Ciclo de implementação do BSC na unidade de negócios selecionada. Para o atendimento do escopo e tempo desta pesquisa foi selecionado um plano de ação para a execução dos demais ciclos da pesquisa-ação;

- Ciclo de implementação do plano de ação priorizado. Foi priorizado o plano de implementação do processo de gerência de requisitos (baseado na área de processo REQM - Requirements Management by CMMI - Capability Maturity Model Integration).

\section{0 desenvolvimento do roteiro proposto}

Esta seção apresenta os principais passos da execução da pesquisa-ação, cujo foco central foi o refinamento do roteiro proposto. Apresenta ainda as percepções e resultados registrados em cada etapa. A Figura 1 apresenta um diagrama de atividade contendo as etapas do roteiro proposto.

0 roteiro está estruturado nas etapas do BSC propostas por Kaplan e Norton:

- Arquitetura de indicadores, cujo objetivo é definir a arquitetura de indicadores;

- Objetivos estratégicos, cujo objetivo é obter o consenso em função dos objetivos estratégicos;

- Escolha e elaboração dos indicadores, cujo objetivo é escolher e elaborar os indicadores;

- Plano de implementação, cujo objetivo é elaborar o plano de implementação.

Nas atividades referentes à escolha e elaboração dos indicadores (Figura 1), estão agrupadas as atividades de definir indicadores. Essas atividades foram adaptadas do PSM conforme descrito na seção Referencial Teórico deste artigo. Nas atividades referentes a plano de implementação foi agregada ao roteiro a aplicação dos conceitos da área de planejamento do PMBOK. 0 objetivo é obter informações como tempo e custo como resultado do planejamento dos planos de ação e utilizar esses critérios na tomada de decisão sobre a priorização dos mesmos.

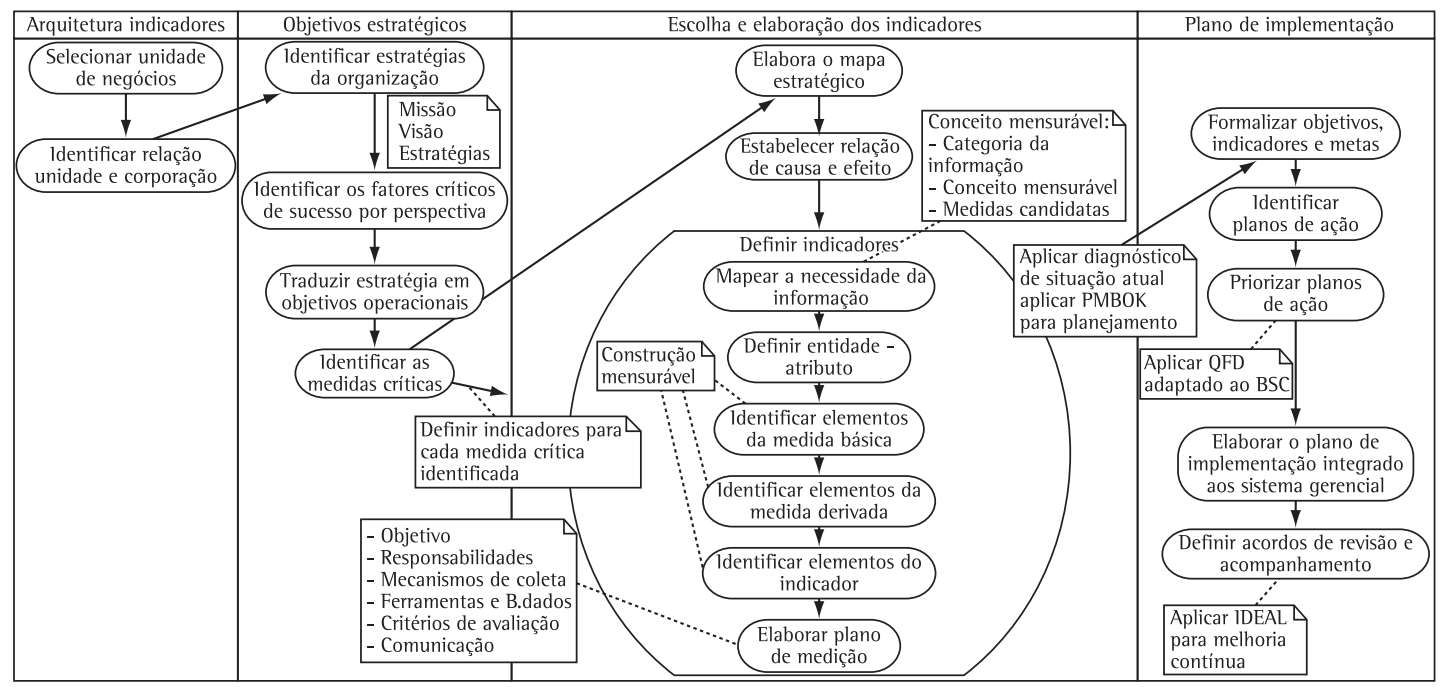

Figura 1. Diagrama de atividades do roteiro proposto. Fonte: os autores. 


\subsection{Execução e controle da pesquisa-ação - $1^{\circ}$ ciclo}

0 ciclo da pesquisa-ação referente à implementação do BSC foi planejado para execução das seguintes atividades:

\subsubsection{Kickoff - Reunião de início das atividades}

Nessa atividade foram definidos os objetivos da implementação do BSC na unidade de negócio, a periodicidade das reuniões e a base documental necessária em cada etapa, além de se reforçar o conceito da pesquisa-ação. 0 grupo concordou que a priorização das decisões teria como critério principal o tempo a ser gasto, pois a pesquisa não poderia sofrer prorrogações. 0 esclarecimento das atividades das próximas etapas foi fundamental para seu planejamento e execução.

Os acordos firmados nessa etapa foram muito importantes, pois as discussões se alongavam e as decisões eram constantemente alteradas. Thiollent (2005) afirma que a pesquisa-ação promove ampla e explícita interação entre pesquisadores e pessoas envolvidas na situação investigada. Um dos envolvidos relatou que as discussões, por vezes, eram retomadas em momentos informais, espontaneamente, demonstrando um real envolvimento dos participantes.

\subsubsection{Definição da arquitetura de indicadores}

Nessa etapa foram esclarecidos os motivos da escolha da unidade organizacional e estudada a missão e estratégia da empresa. Houve pontos de não entendimento ou interpretação diversa, e fizeram-se necessários o alinhamento e o envolvimento da alta administração para esclarecimento.
Os questionamentos propostos pelo BSC referentes aos objetivos financeiros e políticas internas e externas geraram necessidade de refinamento no plano de negócios da unidade. A Figura 2 ilustra a estrutura organizacional da unidade de negócios pesquisada.

A unidade está estruturada em três células. A primeira é responsável pela inovação dos produtos através da identificação das necessidades de customização do produto. É responsável, ainda, por manter as versões do produto devidamente documentadas e pelo treinamento dos usuários na utilização do produto.

A segunda célula refere-se ao atendimento de clientes. Após a implementação do produto, os clientes são orientados a utilizar o serviço de Help-Desk como canal de comunicação referente a dúvidas de utilização ou não conformidade do produto.

A terceira célula é responsável pela implementação do código do produto. Ela é acionada pelas duas primeiras células, pois existem solicitações de novos desenvolvimentos ou manutenções evolutivas ou corretivas. Caso a demanda seja superior à capacidade produtiva da célula, a fábrica de software é acionada para atender a demanda.

Houve muita discussão sobre os papéis e responsabilidades das células. 0 que foi percebido é que no dia a dia havia sobreposição de responsabilidades e por vezes todos executavam um pouco de tudo. Esse alinhamento trouxe benefícios imediatos para a operação.

Nessa etapa ficou acordado que as reuniões seriam preparadas e executadas de forma objetiva, evitando longas discussões sem resultados efetivos. 0 foco é bastante importante para o melhor aproveitamento do tempo dedicado pelos participantes. A formalização das decisões era

\section{Strategic products}

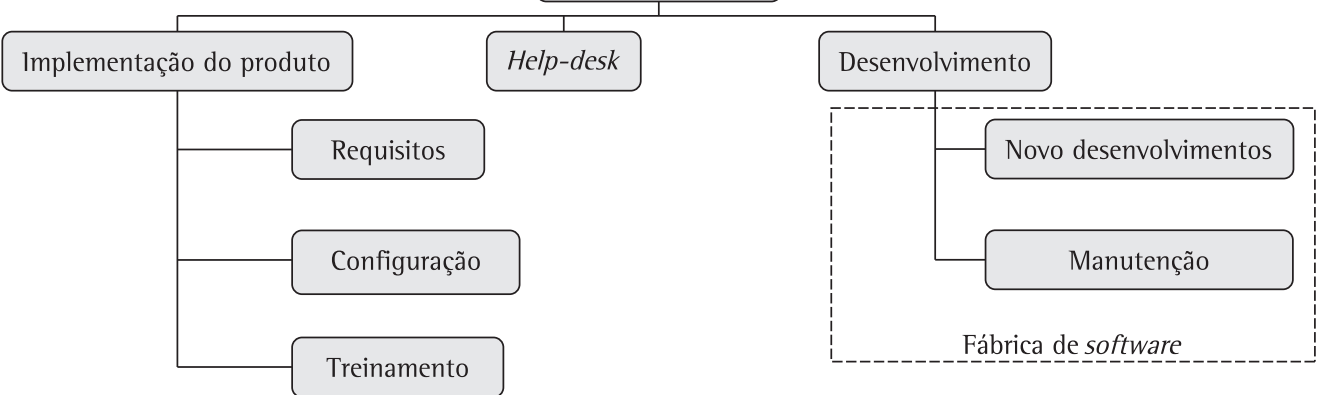

Figura 2. Estrutura organizacional da unidade de negócios. Fonte: os autores. 
distribuída a todos antes do próximo encontro. A seriedade do trabalho reforçou o compromisso dos participantes, pois nem todos puderam comparecer a todas as reuniões. A utilização de documentos previamente formatados contribuiu na objetividade dos produtos a serem gerados nas reuniões.

0 Quadro 2 apresenta o roteiro proposto para a etapa 1 com o desdobramento das atividades e os produtos previstos.

\subsubsection{Obtenção do consenso sobre os objetivos estratégicos}

Segundo Kaplan e Norton (2004), o principal objetivo nessa etapa é debater a declaração de missão, visão e fatores críticos de sucesso e de estratégia da unidade até que o consenso seja alcançado.

Nessa etapa foram abordadas questões sobre o crescimento do mercado, ofertas e inovações tecnológicas. A empresa pesquisada utilizava informações de uma renomada organização de pesquisas mercadológicas como referência. Nesse material foram identificados os três principais concorrentes e analisados os diferenciais de cada um em relação aos produtos oferecidos pela unidade de negócios.

Os conceitos sobre missão, visão e objetivos estratégicos do BSC foram apresentados. 0 reforço e o alinhamento sobre cada conceito foram necessários, pois geraram muito questionamento no momento de sua definição.

0 Quadro 3 ilustra a declaração da missão da organização, a missão e a estratégia da unidade de negócios conforme consenso do grupo.

Nessa etapa, Kaplan e Norton (2004) recomendam identificar as questões sobre os problemas, riscos e conflitos na implementação. Os potenciais conflitos entre as unidades de negócios da empresa foram considerados, assim como o conflito nas parcerias estratégicas estabelecidas pela organização.
Thiollent (2005) afirma que um dos objetivos da pesquisa-ação é aumentar o conhecimento dos envolvidos sobre determinadas situações. A necessidade de alinhamento sobre os modelos de processos que a empresa determinou como referência da política de qualidade levaram à realização de workshops extras sobre RUP (Rational Unified Process), REQM (Requirements Management) e CMMl (Capability Maturity Model Integration).

O Quadro 4 ilustra os objetivos estratégicos para cada perspectiva.

Os fatores críticos de sucesso e as medidas críticas por perspectiva foram exaustivamente discutidos. As percepções e entendimento dos participantes eram diferentes, o que levou a longas discussões. Outra questão importante foi a necessidade de restrição da quantidade dos fatores críticos e medidas. Surgiram muitas dúvidas sobre como medir e quais medidas estabelecer.

0 Quadro 5 ilustra os fatores críticos de sucesso e as medidas críticas identificados para a unidade de negócios nas quatro perspectivas propostas pelo BSC.

Nessa etapa percebeu-se que ter acesso à informação da estratégia da organização motivou a equipe. Ficou claro para todos que a organização possui as estratégias traçadas, mas existe falha na sua comunicação. 0 modelo do BSC contribuiu na identificação de pontos a detalhar no plano de negócios da organização e na comunicação dessas estratégias aos níveis da organização.

As reuniões periódicas com a diretoria da empresa foram realizadas para posicionamento sobre 0 andamento da pesquisa. A diretoria percebeu que a implementação dessas etapas do BSC contribuiu para a institucionalização das políticas estabelecidas pela organização. As atividades e etapas estabelecidas pelo BSC permitiram o entendimento gradativo dos conceitos e consequentemente o refinamento do mapa estratégico e indicadores.

0 Quadro 6 apresenta o roteiro proposto para a etapa 2 com o desdobramento das atividades e os produtos previstos.

Quadro 2. Etapa 1 do roteiro proposto.

\begin{tabular}{|c|c|c|}
\hline Etapa & Atividades & Produto \\
\hline \multirow[b]{2}{*}{$\begin{array}{c}\text { 1. Definição } \\
\text { da arquitetura } \\
\text { de indicadores }\end{array}$} & $\begin{array}{l}\text { 1.1. Selecionar a unidade organizacional adequada } \\
\text { - Identificar uma unidade que permita inovação, operações, marketing, vendas e serviços }\end{array}$ & $\begin{array}{l}\text { Caracterização da } \\
\text { unidade de negócio }\end{array}$ \\
\hline & $\begin{array}{l}\text { 1.2. Identificar as relações entre a unidade de negócios e a corporação para: } \\
\text { - Entender a missão e a estratégia da organização; } \\
\text { - Identificar objetivos financeiros (crescimento, lucratividade, fluxo de caixa, volume de extração); } \\
\text { - ldentificar políticas internas e externas (segurança, ambiente, funcionários, qualidade, } \\
\text { competitividade de preço e inovação) }\end{array}$ & $\begin{array}{l}\text { Organograma } \\
\text { Alinhamento sobre } \\
\text { as políticas da } \\
\text { organização }\end{array}$ \\
\hline
\end{tabular}

Fonte: os autores. 


\subsubsection{Escolha e elaboração dos indicadores}

A atividade de estabelecer a relação de causa e efeito entre os objetivos proporcionou a revisão e o ajuste destes. 0 mapa estratégico preliminar foi

Quadro 3. Declaração da visão estratégica.

\begin{tabular}{|c|l|}
\hline \multicolumn{2}{|c|}{ Qual é a nossa visão de futuro? } \\
\hline $\begin{array}{c}\text { Declaração } \\
\text { de missão da } \\
\text { organização }\end{array}$ & $\begin{array}{l}\text { Nosso propósito é tratar a informação do ponto } \\
\text { de vista tecnológico, indo ao encontro dos anseios } \\
\text { desafiadores da sociedade. Cremos que seremos } \\
\text { vitoriosos estimulando os nossos talentos humanos } \\
\text { e excedendo a satisfação de nossos clientes. }\end{array}$ \\
\hline $\begin{array}{c}\text { Declaração } \\
\text { de missão da } \\
\text { unidade de } \\
\text { negócio }\end{array}$ & $\begin{array}{l}\text { Modernizar e capacitar as empresas em gestão } \\
\text { estratégica e tática, assim como, tornar-se uma } \\
\text { referência deste assunto no mercado }\end{array}$ \\
\hline $\begin{array}{c}\text { Estratégia da } \\
\text { unidade }\end{array}$ & $\begin{array}{l}\text { 1. Foco no risco operacional das instituições } \\
\text { financeiras; }\end{array}$ \\
$\begin{array}{l}\text { 2. Foco em risco operacional de outros segmentos; } \\
\text { 3. Criar uma oferta de produtos diferenciada; }\end{array}$ \\
\hline
\end{tabular}

Fonte: os autores.

Quadro 4. Declaração dos objetivos estratégicos.

\begin{tabular}{|c|c|c|c|}
\hline \multicolumn{4}{|c|}{ Objetivos } \\
\hline $\begin{array}{c}\text { Perspectiva } \\
\text { financeira }\end{array}$ & $\begin{array}{c}\text { Perspectiva } \\
\text { do cliente }\end{array}$ & $\begin{array}{c}\text { Perspectiva } \\
\text { interna }\end{array}$ & $\begin{array}{c}\text { Inovação e } \\
\text { aprendizado }\end{array}$ \\
\hline $\begin{array}{c}\text { Aumentar a } \\
\text { rentabilidade }\end{array}$ & $\begin{array}{c}\text { Perceber a } \\
\text { satisfação do } \\
\text { cliente }\end{array}$ & $\begin{array}{c}\text { Aumentar } \\
\text { eficiência no } \\
\text { atendimento }\end{array}$ & $\begin{array}{c}\text { Programa de } \\
\text { treinamento }\end{array}$ \\
\hline $\begin{array}{c}\text { Aumentar a } \\
\text { receita }\end{array}$ & Reter o cliente & $\begin{array}{c}\text { Aumentar } \\
\text { eficácia na } \\
\text { gestão dos } \\
\text { serviços }\end{array}$ & $\begin{array}{c}\text { Desenvolver e } \\
\text { formar talentos }\end{array}$ \\
\hline & $\begin{array}{c}\text { Conquistar } \\
\text { novos clientes }\end{array}$ & $\begin{array}{c}\text { Potencializar } \\
\text { o benefício } \\
\text { em relação ao } \\
\text { custo }\end{array}$ & $\begin{array}{c}\text { Programa de } \\
\text { Retenção e } \\
\text { fidelização de } \\
\text { colaboradores }\end{array}$ \\
\hline
\end{tabular}

Fonte: os autores. apresentado e validado com o grupo. A Figura 3 ilustra o mapa e análise de correlação entre os objetivos.

No modelo proposto pelo BSC, os indicadores são relacionados aos objetivos nessa etapa. $\mathrm{Na}$ prática, foi observada a necessidade de aplicar os conceitos do PSM já nessa etapa, facilitando a transformação de medida crítica em medida básica e posteriormente em indicador. 0 Quadro 7 apresenta o scorecard da estratégia preliminar definido para a unidade de negócios.

Observe no Quadro 7 que 0 indicador investimentos no processo de melhoria de software foi definido na perspectiva de processos internos.

Thiollent (2005) afirma que o objetivo da pesquisa-ação consiste em resolver ou pelo menos esclarecer os problemas da situação observada. Durante o workshop, foi relatado por um dos integrantes da equipe sobre o constante questionamento de clientes referente aos seus direitos na aquisição do software ou serviços. A evolução dessa discussão fez o grupo concluir que havia fragilidade no processo referente à definição do escopo dos contratos. Aplicando-se os conceitos do PSM, o indicador investimentos no processo de melhoria de software foi refinado para cumprimento de escopo. 0 conceito de indicador de BSC foi relacionado ao conceito necessidade de informação do PSM.

No PSM são definidas as seguintes informações: necessidade da informação, entidade-atributo, categoria da informação, conceito mensurável e medidas candidatas. 0 Quadro 8 ilustra as informações obtidas no mapeamento sugerido pelo PSM.

Quadro 5. Fatores críticos de sucesso e medidas da unidade de negócios.

\begin{tabular}{|c|c|c|c|c|}
\hline $\begin{array}{l}\text { Se a nossa missão } \\
\text { for bem sucedida } \\
\text { onde nos } \\
\text { diferenciaremos? }\end{array}$ & $\begin{array}{c}\text { Para acionistas } \\
\text { Perspectiva } \\
\text { financeira }\end{array}$ & $\begin{array}{l}\text { Para clientes } \\
\text { Perspectiva do } \\
\text { cliente }\end{array}$ & $\begin{array}{l}\text { Nos processos internos } \\
\text { Perspectiva interna }\end{array}$ & $\begin{array}{l}\text { Na capacidade de inovar e crescer } \\
\text { lnovação e aprendizado }\end{array}$ \\
\hline \multirow{3}{*}{$\begin{array}{l}\text { Quais os fatores } \\
\text { críticos de sucesso? }\end{array}$} & $\begin{array}{l}\text { Crescimento da } \\
\text { receita recorrente }\end{array}$ & $\begin{array}{c}\text { Perceber atitude de } \\
\text { parceria e ser lembrado }\end{array}$ & Oferecer solução diferenciada & $\begin{array}{c}\text { Solução que abrange sistema e } \\
\text { consultoria - agilidade no lançamento }\end{array}$ \\
\hline & Rentabilidade & $\begin{array}{l}\text { Aumentar a carteira de } \\
\text { clientes no segmento } \\
\text { financeiro }\end{array}$ & $\begin{array}{l}\text { Melhoria no atendimento do } \\
\text { cliente (Help-Desk) }\end{array}$ & $\begin{array}{l}\text { Estabelecer parcerias de solução } \\
\text { e de negócios }\end{array}$ \\
\hline & & $\begin{array}{l}\text { Expandir clientes em } \\
\text { outros segmentos }\end{array}$ & $\begin{array}{l}\text { Custo e benefício Revisão do } \\
\text { preços de ferramenta e serviços }\end{array}$ & Capacitação da equipe \\
\hline \multirow{2}{*}{$\begin{array}{l}\text { Quais são as nossas } \\
\text { medidas críticas? }\end{array}$} & $\begin{array}{l}\text { Receita mensal } \\
\text { (vendas e } \\
\text { manutenção) }\end{array}$ & $\begin{array}{l}\text { Número atual de } \\
\text { clientes e estabelecer } \\
\text { meta de crescimento }\end{array}$ & $\begin{array}{l}\text { Número de solicitações e nível de } \\
\text { severidade (definição da política } \\
\text { de atendimento) - horas/custos } \\
\text { gasto no atendimento }\end{array}$ & $\begin{array}{l}\text { Mapa de competência da equipe } \\
\text { (Quantidade de recursos por perfil) }\end{array}$ \\
\hline & $\begin{array}{l}\text { Margem liquida } \\
\text { Margem bruta }\end{array}$ & $\begin{array}{l}\text { Participação em } \\
\text { faturamento no cliente } \\
\text { Nivel satisfação }\end{array}$ & $\begin{array}{l}\text { Identificar concorrentes } \\
\text { fora do cliente }\end{array}$ & $\begin{array}{l}\text { Horas de capacitação da equipe } \\
\text { em novas tecnologias } \\
\text { Horas de capacitação da equipe } \\
\text { no produto }\end{array}$ \\
\hline
\end{tabular}

Fonte: os autores. 
Os elementos solicitados pelo PSM referentes à identificação e caracterização na definição da medida básica funcionaram como questionamentos na escolha e estruturação das medidas. Os conceitos do PSM permitem a validação das medidas críticas proposta pelo BSC e análise de relevância das medidas básicas.

0 Quadro 9 apresenta o scorecard da estratégia refinado com a aplicação dos conceitos do PSM.

A importância de manter o foco nos objetivos e indicadores relevantes mais uma vez foi observada, pois surgiram muitas idéias e sugestões de controles. Foi necessário estabelecer o consenso novamente sobre a quantidade de informações que seriam coletadas e analisadas. 0 diretor executivo da unidade de negócio foi eleito como responsável pela tomada de decisão nos momentos de impasse para que o tempo fosse cumprido.

Os elementos solicitados pelo PSM referentes ao registro e à coleta dos dados permitiram o questionamento sobre a relevância das medidas básicas. Um workshop para discussão e validação

Quadro 6. Etapa 2 do roteiro proposto.

\begin{tabular}{|c|c|c|}
\hline Etapa & Atividades & Produto \\
\hline \multirow{3}{*}{$\begin{array}{l}\text { 2. Obtenção do } \\
\text { consenso sobre } \\
\text { os objetivos } \\
\text { estratégicos }\end{array}$} & $\begin{array}{l}\text { 2.1. Identificar estratégias da organização: } \\
\text { - Realizar a primeira série de entrevistas para: } \\
\text { - Identificar o crescimento de mercado, ambiente competitivo do mercado, concorrentes } \\
\text { e inovações tecnológicas; } \\
\text { - Alinhar conceitos do BSC e conceitos sobre missão, visão e estratégia; } \\
\text { - Obter informações iniciais sobre a estratégia organizacional; } \\
\text { - Direcionar a tradução da estratégia em objetivos operacionais tangíveis; } \\
\text { - Mapear os stakeholders (envolvidos); } \\
\text { - Identificar potenciais conflitos (aspectos estratégicos, objetivos, pessoal ou } \\
\text { interfuncional); } \\
\text { - ldentificar os fatores críticos de sucesso por perspectiva. }\end{array}$ & $\begin{array}{l}\text { - Estratégia da organização } \\
\text { - Alinhamento sobre os } \\
\text { conceitos do BSC, missão, } \\
\text { visão e estratégia }\end{array}$ \\
\hline & $\begin{array}{l}\text { 2.2. Realizar sessão de síntese para: } \\
\text { - Traduzir estratégia em objetivos operacionais; } \\
\text { - Preparar uma relação preliminar de objetivos e medidas; } \\
\text { - Mapear os pontos de conflitos pessoais e organizacionais (resistências); } \\
\text { - Classificar os objetivos nas quatro perspectivas; } \\
\text { - Verificar se a relação preliminar de objetivos retrata a estratégia da unidade; } \\
\text { - Verificar se os objetivos nas quatro perspectivas estão interligados na relação de causa } \\
\text { e efeito. }\end{array}$ & $\begin{array}{l}\text { - Relação preliminar de } \\
\text { objetivos e medidas } \\
\text { - Mapa estratégico preliminar }\end{array}$ \\
\hline & $\begin{array}{l}\text { 2.3. Workshop executivo - Na primeira etapa: } \\
\text { - Identificar as medidas críticas; } \\
\text { - Apresentar a relação preliminar de objetivos e medidas; } \\
\text { - Discutir e complementar objetivos e medidas. }\end{array}$ & $\begin{array}{l}\text { - Objetivos estratégicos para } \\
\text { cada perspectiva } \\
\text { - Lista de fatores críticos de } \\
\text { sucesso e medidas }\end{array}$ \\
\hline
\end{tabular}

Fonte: os autores.

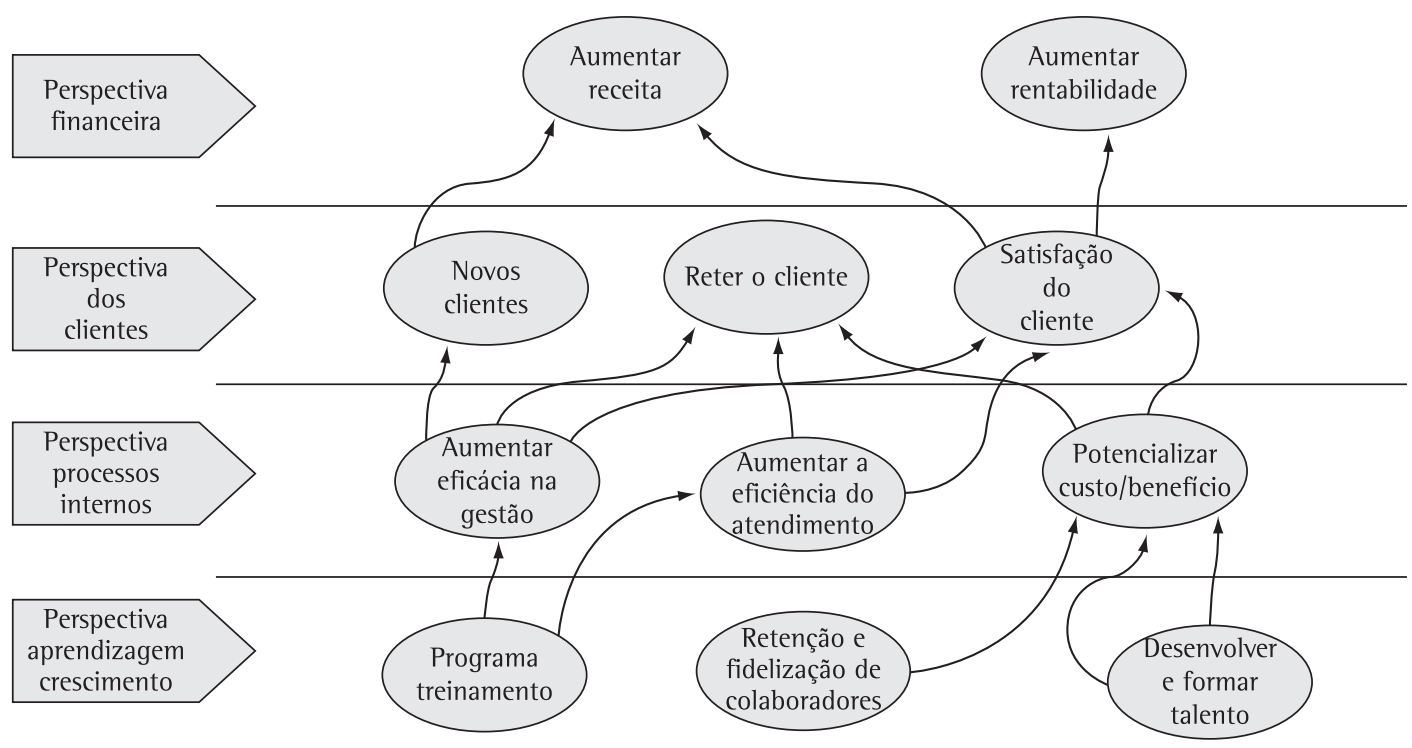

Figura 3. Mapa estratégico da unidade de negócios. Fonte: os autores. 
Quadro 7. Scorecard preliminar da unidade de negócios.

\begin{tabular}{|c|c|c|c|c|}
\hline Perspectiva & Objetivos & Indicador & Meta (\%) & Programa de ação \\
\hline \multirow{2}{*}{ Financeira } & $\begin{array}{c}\text { Aumentar a } \\
\text { rentabilidade }\end{array}$ & Aumentar a margem bruta & 2 & Melhorar sistema de informação \\
\cline { 2 - 5 } & Aumentar a receita & Aumentar a receita & 20 & 90 \\
\hline Clientes & Satisfação do cliente & $\begin{array}{c}\text { Feedback do cliente/ } \\
\text { Grau de satisfação }\end{array}$ & $\begin{array}{c}\text { Implementar questionário/entrevista } \\
\text { visando obter a satisfação do cliente }\end{array}$ \\
\hline Processos internos & $\begin{array}{c}\text { Aumentar a eficácia } \\
\text { na gestão }\end{array}$ & $\begin{array}{c}\text { Investimentos em processos de } \\
\text { melhoria de software }\end{array}$ & $\begin{array}{c}\text { Implementar o processo da gerência de } \\
\text { requisitos (Controlar mudanças) }\end{array}$ \\
\hline Aprendizagem & $\begin{array}{c}\text { Programa de } \\
\text { treinamento }\end{array}$ & Investimentos em capacitação & 5 & $\begin{array}{c}\text { Treinamento em gerência } \\
\text { de requisitos }\end{array}$ \\
\hline
\end{tabular}

Fonte: os autores.

Quadro 8. Mapeamento da necessidade das informações.

\begin{tabular}{|c|c|c|}
\hline Necessidade da informação & Cumprimento de escopo & \\
\hline Entidade - Atributo & $\begin{array}{l}\text { Demandas solicitações de mudança } \\
\text { das demandas }\end{array}$ & \\
\hline Categoria de informação & Progresso e prazo & \\
\hline Conceito mensurável & Progresso da unidade de trabalho & $\begin{array}{l}\text { Medidas candidatas } \\
\text { Requisitos de mudança abertos } \\
\text { Requisitos de mudança resolvidos }\end{array}$ \\
\hline
\end{tabular}

Fonte: os autores.

Quadro 9. Scorecard refinado para a perspectiva e processos internos.

\begin{tabular}{|c|c|c|c|c|}
\hline Perspectiva & Objetivos & Indicador & Meta (\%) & Programa de ação \\
\hline Processos internos & $\begin{array}{c}\text { Aumentar a eficácia } \\
\text { na gestão }\end{array}$ & $\begin{array}{c}\text { Cumprimento do } \\
\text { escopo }\end{array}$ & 100 & $\begin{array}{c}\text { Implementar o processo da gerência de requisitos } \\
\text { (Controlar mudanças) }\end{array}$ \\
\hline
\end{tabular}

Fonte: os autores.

do mapa estratégico, objetivos estratégicos e indicadores foi realizado. 0 embasamento dos indicadores gerados foi fundamental para a obtenção de consenso. 0 envolvimento dos responsáveis pela integração entre a coleta de dados e os sistemas gerenciais da organização deve ocorrer no momento da definição das medidas críticas. A obtenção dos dados impacta diretamente o plano de implementação do BSC. Portanto, qualquer problema na coleta de dados torna-se risco para o plano de implementação e a sua solução deve ser priorizada.

0 Quadro 10 apresenta o roteiro proposto para a etapa 3 com o desdobramento das atividades e os produtos previstos.

\subsubsection{Elaboração do plano de implementação}

Nessa etapa o mapa estratégico, os objetivos estratégicos, os indicadores, as metas e os planos de ação foram formalizados. Segundo Kaplan e Norton (2004), é comum a identificação de um número incontável de ações a serem executadas. A atividade de definir os planos de ação demandou tempo devido aos questionamentos dos envolvidos. 0 planejamento da integração dos sistemas gerenciais com a coleta de dados necessária foi um dos itens mais demorados.

Os planos de ação identificados foram: melhorar sistema de informação; implementar questionário/ entrevista visando obter a satisfação do clientes; implementar o processo da gerência de requisitos (controlar mudanças) e treinamento em gerência de requisitos. Houve muita discussão sobre a priorização dos planos, pois havia divergência de entendimento sobre os critérios de priorização.

0 planejamento dos planos de ação, utilizando os conceitos do PMBOK, padronizou a sua forma de elaboração e apresentação. Dessa forma, critérios como tempo e custo foram utilizados como critérios para a priorização dos mesmos.

0 Quadro 11 apresenta o roteiro proposto para a etapa 4 com o desdobramento das atividades e os produtos previstos.

\subsection{Execução e controle da pesquisa-ação $-2^{\circ}$ ciclo}

Conforme definido no planejamento da pequisa-acão, o plano de ação priorizado foi 
Quadro 10. Etapa 3 do roteiro proposto.

\begin{tabular}{|c|c|c|}
\hline Etapa & Atividades & Produto \\
\hline & $\begin{array}{l}\text { 3.1. Reuniões dos subgrupos: } \\
\text { - Elaborar o mapa estratégico; } \\
\text { - Refinar a descrição dos objetivos estratégicos; } \\
\text { - Alinhar conceitos sobre indicares (PSM); } \\
\text { - Relacionar indicadores para os objetivos; } \\
\text { - ldentificar as fontes de informação; } \\
\text { - Identificar as relações críticas entre os indicadores. }\end{array}$ & $\begin{array}{l}\text { - Mapa estratégico e análise de correlação Scorecard da } \\
\text { estratégia } \\
\text { - Lista de medição dos indicadores } \\
\text { - Roteiro de medição dos indicadores (PSM) }\end{array}$ \\
\hline $\begin{array}{l}\text { 3. Escolha e elaboração } \\
\text { dos indicadores }\end{array}$ & $\begin{array}{l}\text { 3.2. Workshop executivo- segunda etapa. Discutir sobre: } \\
\text { - A visão; } \\
\text { - A estratégia; } \\
\text { - Os objetivos; } \\
\text { - Os indicadores; } \\
\text { - Estabelecer a relação de causa e efeito; } \\
\text { - Definir indicadores (PSM); } \\
\text { - Mapear a necessidade da informação; } \\
\text { - Definir Entidade-Atributo; } \\
\text { - ldentificar elementos da medida básica; } \\
\text { - ldentificar elementos da medida derivada; } \\
\text { - ldentificar elementos do Indicador; } \\
\text { - Elaborar plano de medição }\end{array}$ & $\begin{array}{l}\text { - Mapa estratégico e análise de correlação } \\
\text { - Scorecard da estratégia refinados } \\
\text { - Lista de medição dos indicadores } \\
\text { - Roteiro de medição dos indicadores (PSM) } \\
\text { - Plano de medição }\end{array}$ \\
\hline
\end{tabular}

Fonte: os autores.

Quadro 11. Etapa 4 do roteiro proposto.

\begin{tabular}{|c|c|c|}
\hline Etapa & Atividades & Produto \\
\hline \multirow{3}{*}{$\begin{array}{l}\text { 4. Elaboracão } \\
\text { do plano de } \\
\text { implementação }\end{array}$} & $\begin{array}{l}\text { 4.1. Desenvolver o plano de implementação para: } \\
\text { - Formalizar as metas e indicadores; } \\
\text { - Definir a coleta de dados; } \\
\text { - Definir a periodicidade de comunicação; } \\
\text { - Identificar os planos de ação; } \\
\text { - Priorizar os planos de ação; } \\
\text { - Obter o estado atual dos planos de ação. }\end{array}$ & $\begin{array}{l}\text { - Plano de implementação } \\
\text { - Lista de medição dos indicadores } \\
\text { - Roteiro de medição dos indicadores (PSM) } \\
\text { - Plano de medição }\end{array}$ \\
\hline & $\begin{array}{l}\text { 4.2. Workshop executivo- segunda etapa: } \\
\text { - Validar o plano de implementação; } \\
\text { - Validar programas de ação preliminares para alcançar as metas. }\end{array}$ & $\begin{array}{l}\text { - Plano de implementação refinado } \\
\text { - Planejamento dos planos de ação (PMBOK) } \\
\text { - Planejamento dos planos de ação }\end{array}$ \\
\hline & $\begin{array}{l}\text { 4.3. Finalizar o plano de implementação: } \\
\text { - Definir integração do plano de implementação ao sistema gerencial } \\
\text { da organização; } \\
\text { - Definir os acordos sobre a revisão do BSC (processo, responsável e } \\
\text { periodicidade). }\end{array}$ & - Plano de implementação refinado \\
\hline
\end{tabular}

Fonte: os autores.

a implementação da gerência de requisitos. 0 investimento estimado abrangeu o treinamento e a implementação do processo já definido pela empresa num prazo de dois meses.

Os objetivos deste ciclo foram definidos, assim como a periodicidade das reuniões e a base documental necessária em cada etapa. Os objetivos estabelecidos foram:

- Fortalecer os conceitos da gerência de requisitos;

- Implementar a sua prática através da identificação dos requisitos de cada projeto;

- Monitorar o indicador do número de solicitações de mudança por projeto;

- Identificar o impacto financeiro das solicitações de mudança nos projetos;

- Relatar as atividades executadas;

- Relatar os resultados obtidos.

0 workshop para alinhamento dos conceitos do REQM - Requirements Management do CMMI foi realizado. 0 objetivo foi fortalecer os conceitos para implementar a prática imediata da gerência de requisitos nos projetos da unidade.

A análise dos projetos em andamento identificou 22 projetos ativos. Entre esses, cinco foram escolhidos utilizando os seguintes critérios:

- Baixo nível de satisfação do cliente com o atendimento;

- Resultado (resultado = faturamento - custo operacional - impostos).

Após a análise, à luz dos conceitos da gerência de requisitos, os seguintes dados foram registrados:

- Dois projetos em andamento e ainda sem ocorrência de mudança de requisitos. No entanto, um deles já mostrava forte potencial de mudança de requisitos;

- Três projetos com ocorrências de mudança de requisitos. 
Os requisitos definidos para o projeto foram mapeados e foram identificados os requisitos já entregues. Um relatório para a análise dos resultados de faturamentos dos projetos foi elaborado. Os projetos com mudança de requisitos comprometiam em 30\% do faturamento total. Por solicitação da empresa foco desta pesquisa, os números não foram divulgados neste trabalho. As estratégias de renegociação com cada cliente foram definidas. Por fim, dos cinco projetos analisados, dois foram renegociados, um cancelado e dois ficaram em observação.

\subsection{Encerramento da pesquisa-ação}

A pesquisa-ação, segundo Thiollent (2005), não se limita a uma forma de ação: pretende-se aumentar o conhecimento dos pesquisadores e o conhecimento ou o nível de consciência das pessoas e grupos participantes. O BSC é um sistema de gestão baseado em indicadores que impulsionam o desempenho, proporcionando à organização uma visão de negócio abrangente. A implementação da gerência de requisitos proporcionou um aumento na maturidade da equipe na identificação das mudanças dos requisitos. Essa ação proporcionou o embasamento necessário para renegociação com o cliente. A equipe percebeu os benefícios da gerência de requisitos e ficou motivada para manter a prática do processo. 0 alinhamento entre as ações em melhoria de processo de software (ampliar a eficácia da gestão através da implementação da gerência de requisitos) e os objetivos estratégicos da empresa (aumentar receita) foram mapeados através dos resultados observados. A identificação das mudanças dos requisitos permitiu o embasamento para renegociação que, por sua vez, resultou no aumento do faturamento da empresa. Portanto, podemos observar que a relação de causa e efeito garante um encadeamento entre os objetivos das perspectivas de modo a refletir as relações de causa e efeito assumidas na formulação das estratégias

Recapitulando, no mapa estratégico a perspectiva referente a processos internos direcionou para a revisão dos processos em busca de eficácia. 0 resultado da pesquisa demonstrou que as ações realizadas em melhoria de processos, dentro da perspectiva de processos internos, impactaram diretamente as perspectivas financeiras e do cliente. As ações em melhoria dos processos de software fizeram aumentar a satisfação do cliente, pois foi identificado o incômodo dele referente ao não cumprimento do escopo. 0 processo foi revisado e foi implementado o conceito de identificação dos requisitos, tornando mensurável o gerenciamento do escopo. 0 monitoramento das mudanças de requisitos proporcionou o embasamento para a negociação de mudança de escopo junto aos clientes.
0 relacionamento entre a empresa e o cliente tornou-se profissional e maduro, aumentando a relação de confiança. Os valores renegociados não são apresentados por solicitação da empresa, foco desta pesquisa. No entanto, foi analisado o investimento na implementação da gerência de requisitos em relação ao resultado financeiro das renegociações com os clientes utilizando a abordagem da mudança de requisitos. A proporção foi a seguinte: para cada $R \$ 1,00$ investido foram recuperados $R \$ 4,00$. Essa foi a forma de análise dos investimentos efetuados pela empresa. 0 investimento proporcionou um retorno real sobre o faturamento da organização e foi acompanhado pela alta administração da empresa através do mapa estratégico. 0 mapa estratégico mostrou-se eficiente ao representar o impacto positivo do investimento realizado na perspectiva dos processos internos e nas perspectivas financeira e do cliente.

Thiollent (2005) enfatiza que um maior conhecimento sobre a situação direciona a ações mais efetivas. No entanto, as exigências do cotidiano frequentemente limitam o tempo de dedicação ao conhecimento. Acrescenta, ainda, que há casos em que o objetivo é a tomada de consciência dos agentes implicados na atividade investigada. Nesse caso, não se trata apenas de resolver um problema imediato, e sim desenvolver a consciência da coletividade nos planos políticos ou culturais a respeito dos problemas importantes. 0 nível de aprendizado do pesquisador e dos participantes da pesquisa foi aprimorado e diminuiu a resistência habitual em movimentos de mudança organizacional. Os participantes tiveram a oportunidade de definir o ajuste no processo para atender as necessidades da empresa.

\section{Conclusão}

0 roteiro desenvolvido e avaliado mostra a viabilidade técnica de implementar o alinhamento estratégico de negócios com a melhoria de processo em empresas desenvolvedoras de software. A aplicação da pesquisa-ação permitiu, por outro lado, que se desenvolvesse maior conhecimento sobre este processo e como ele pode ser efetivado nas organizações. 0 roteiro proposto foi ajustado incorporando as considerações identificadas durante a pesquisa, resultando no roteiro final possível de ser aplicado em diferentes empresas de software.

A implementação, mesmo que parcial do BSC, permite o acesso à informação da estratégia da organização aos interessados. 0 que foi percebido é que a organização possui as estratégias traçadas, mas existe falha na sua comunicação. 0 roteiro proposto contribuiu na identificação de pontos a detalhar no plano de negócios da organização e 
na institucionalização das políticas estabelecidas pela organização. Durante a aplicação do roteiro foi possível demostrar como as ações em melhoria de processo resultaram no aumento da receita da organização.

Conforme relatado, o planejamento dos planos de ação utilizando os conceitos do PMBOK padronizou sua forma de elaboração e apresentação. Dessa maneira, critérios como tempo e custo foram utilizados para a tomada de decisão sobre a priorização dos mesmos.

A aplicação dos conceitos do PSM adaptado ao Balanced Scorecard permitiu gerenciar os indicadores de investimentos. Essa aplicação proporcionou a orientação e detalhamento necessários para a definição e monitoramento dos indicadores. A etapa de definição da coleta de dados é muito crítica, pois trata-se de risco para a implementação do BSC.

A pesquisa-ação contribuiu, de fato, para o aprimoramento do nível de aprendizado dos participantes e na tomada de consciência sobre as situações apresentadas. A oportunidade de atuação efetiva na estratégia da organização motivou os participantes e fez diminuir a resistência habitual em movimentos de mudança organizacional.

\section{Referências}

BRASIL. Ministério de Ciência e Tecnologia - MCT. Notícias de TR: crescem investimentos das empresas em T1. 2005. Disponível em: <http:r//www.mct.gov.br/Temas/info/Imprensa/Noticias_5/ Investimentos_5.htm>. Acesso em: 01 out. 2005.

CARD, D. Integrating practical software measurement and balanced scorecard. In: INTERNATIONAL COMPUTER SOFTWARE AND APPLICATIONS CONFERENCE - IEEE, 2003. Proceedings...

FERNANDES, A. A.; ABREU, V. F. Implantando a governança de TI. Rio de Janeiro: Brasport, 2006. 338 p.

GUERRERO, F.; ETEROVIC, Y. Adopting de SW-CMM in a small it organization. IEEE SOFTWARE, p. 29-35, Jul/Aug 2004.

KAPLAN, R. S.; NORTON, D. P. A estratégia em ação - Balanced Scorecard. 21. ed. Rio de Janeiro: Campus, 2004. 344 p.
LAURINDO, F. J. B. Estratégia e tecnologia da informação: uma visão integrada. In: FUSCO, J. P. A. (Org.). Tópicos emergentes em engenharia de produção. São Paulo: Arte e Ciência, 2003. v. $2.379 \mathrm{p}$.

LAURINDO, F. J. B. Um estudo sobre a avaliação da eficácia da tecnologia da informação nas organizações. 2000.189 f. Tese (Doutorado em Engenharia da Produção)-Universidade de São Paulo, Escola Politécnica, São Paulo, 2000.

MAIR, S. A balanced scorecard for a small software group. IEEE Software, v. 22, n. 3, p. 21-27, 2002.

MONTGOMERY, C. A.; PORTER, M. Estratégia: a busca da vantagem competitiva. 5. ed. Rio de Janeiro: Campus, 1998. 501 p.

MURUGAPPAN, M.; KEENI, G. Blending CMM and Six Sigma to meet business goals. IEEE Software, v. 25, n. 6, p. 42-48, 2003.

MUSCAT, A. R. N.; FLEURY, A. 1Q\&P's na indústria brasileira. Revista Indicadores da Qualidade e Produtividade, v. 1, n. 1, p. 81-107, 1993.

PAPALEXANDRIS, A. et al. An integrated methodology for putting the balanced scorecard into action. European Management Journal, v. 23, n. 2, p. 214-227, 2005.

PORTER, M. Estratégia competitiva. 7. ed. Rio de Janeiro: Campus, 1986. $322 \mathrm{p}$.

POSSI, M. Capacitação em gerenciamento de projetos. Rio de Janeiro: Brasport, 2004.

PRACTICAL SOFTWARE AND SYSTEMS MEASUREMENT - PSM. Methods of operation. PSM, 2006. Draft version 2.6.

PRESSMAN, R. Engenharia de software. 3. ed. São Paulo: Makron Books, 1992. $289 \mathrm{p}$

PROJECT MANAGEMENT INSTITUTE - PMI. A guide to the project management body of knowledge (PMBOK Guide). $4^{\text {th }}$ ed. PA, USA: Project Management Institute, 2008.

SHIBUYA, M.K. Decisão Baseada no Balanced Scorecard. In COSTA NETO, P. L. 0. (coordenador). Qualidade e competência nas decisões. São Paulo: Edgard Blucher, 2007. 496 p.

SOMMERVILLE, 1. Software engineering. $8^{\text {th }}$ ed. Addison-Wesley, 2007.

TAKASHINA, N. T.; FLORES, M. C. Indicadores da qualidade e do desempenho. Rio de Janeiro: Qualimark, 1999. 189 p.

THIOLLENT, M. Metodologia da pesquisa-ação. 14. ed. São Paulo: Cortês, 2005. $178 \mathrm{p}$.

VAHANIITTY, J.; RAUTIAINEN, K. Towards an approach for managing the development portfolio in small product-oriented software companies. In: INTERNATIONAL CONFERENCE ON SYSTEM SCIENCES, Hawaii, 2005. Proceedings...

VELOSO, F.; BOTELHO, A.; GIANELLI, B. Slicing the knowledgebased economy in Brazil, China and India: a tale of three software industries. 2003. Brazilian Government grant to study the development of the local software industry. Mimeo.

\title{
Alignment between the business strategy and the software processes improvement: a roadmap for the implementation
}

\begin{abstract}
The actions of the software products and processes improvement, for a better attendance of the business objectives of an organization, must be associated to the competitive market strategies. This paper describes a roadmap that translates the strategic objectives of the software organizations in managed process pointers. The Balanced Scorecard (BSC) and the Practical Software Measurement (PSM) are the basis of the proposed roadmap. This study is based on the concepts a bibliographical research and the research-action application. The research-action strategy gives refinement to the roadmap, enables the participants to learn and improves the method application. The execution of the methodological stages resulted in the definition of the strategic map and its development in the studied software organization. The final result is a roadmap that allows the implementation of an alignment between the business strategy and the processes improvement in software companies.
\end{abstract}

Keywords

Service business strategy. Software processes improvement. BSC. PSM. 